Ana Lennar Pereira

Helaísa B. Damingues

Jũan Rui Pita

Dswaldo Salaverry
A Natureza as suas Histórias e os seus Caminhos

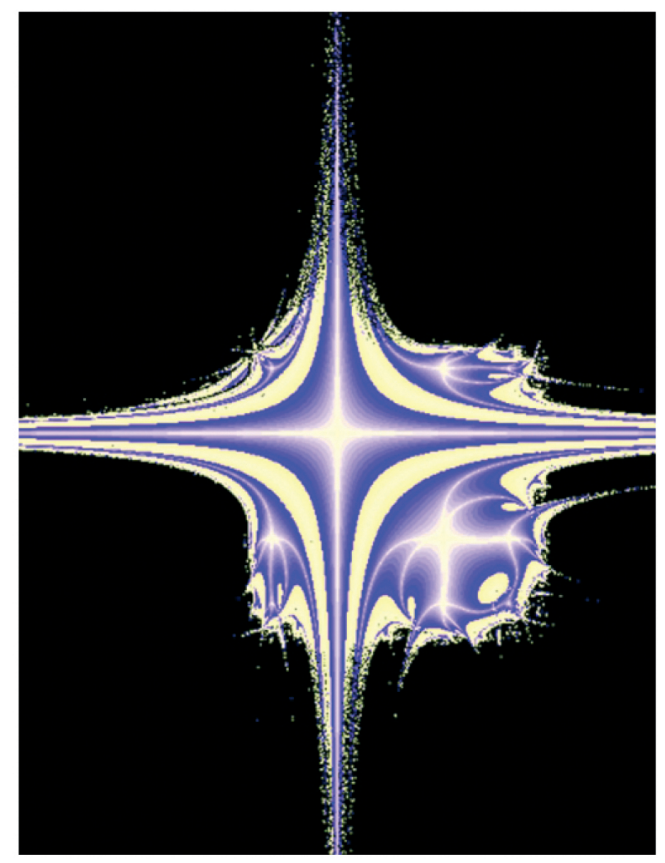


(Página deixada propositadamente em branco) 


\section{ANA LEDNDR PEREIRA \\ HELIISA BERTLL DIMINELESS \\ JIÃ̄ RU PITA \\ GSWALDO SALAVERRY GARCIA}

\section{A NATUREEZA, \\ AS SUAS HISTÓR|AS \\ E IS SELS CAMINHIS}

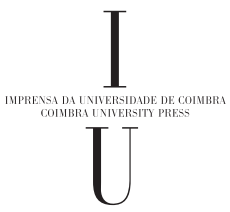

- colmbra 2006 
(Página deixada propositadamente em branco) 
(Página deixada propositadamente em branco) 


\section{Coordenação Científica da Colecção Ciências e Culturas}

João Rui Pita e Ana Leonor Pereira

Os originais enviados são sujeitos a apreciação científica por referees

\section{Coordenação Editorial}

Maria João Padez Ferreira de Castro

\section{Edição}

Imprensa da Universidade de Coimbra

Email: impresauc@ci.uc.pt

URL: http://www.imp.uc.pt • Normas de publicação de colecções

Design

António Barros

Pré-Impressão

António Resende

Imprensa da Universidade de Coimbra

Capa

Ernesto Melo e Castro

Sem título, 2003

Fractais originais gerados no Fractint

Tratados no Photoshop 7.0

Col. António Barros, Coimbra

Impressão e Acabamento

SerSilito $•$ Maia

\section{ISBN}

978-989-8074-13-3

\section{Depósito Legal}

$263187 / 07$

Obra publicada com a colaboração de:

2

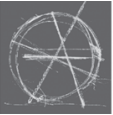

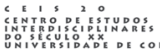

Obra publicada com o apoio de:

FCT Fundação para a Ciência e a Tecnologia

MINISTÉRIO DA CIÊNCIA, TECNOLOGIA E ENSINO SUPERIOR Portugal

Programa Operacional Ciência, Tecnologia, Inovação do Quadro Comunitário de Apoio III

(C) 2006, Imprensa da Universidade de Coimbra 


\author{
Ana Leonor Pereira \\ Faculdade de Letras e CEIS20, Universidade de Coimbra, Portugal
}

\title{
A ReCEPÇÃo do DARWINISMO EM PORTUGAL ${ }^{1}$
}

A geologia de Lyell foi uma peça fundamental na elaboração da teoria darwiniana, o que é notório na Origem das Espécies e foi reconhecido pelo próprio Darwin na sua autobiografia $^{2}$. De resto, a construção da teoria da descendência com modificaçôes seria impensável se Darwin não possuísse um bom nível de conhecimentos geológicos. $\mathrm{Na}$ Universidade de Edimburgo, que frequentou entre 1825 e 1827, e onde era suposto estudar medicina, por decisão paterna, Darwin dedicou-se à geologia e o mesmo ocorreu na Universidade de Cambridge entre 1828 e 1831 onde alcançou o diploma de «Bachelor of Arts». Pode dizer-se que, em Cambridge, em vez de estudar teologia como lhe determinara o considerado médico Robert Waring Darwin, seu pai, o jovem Charles dava livre curso à sua vocação genuína ${ }^{3}$. Durante a viagem do Beagle (1831-1836), Darwin leu e estudou os Principles of geology de Lyell ${ }^{4}$ o que, a par das pesquisas feitas no terreno, de geologia ${ }^{5}$, biogeografia e ecologia, foi, talvez, determinante da emergência da teoria da descendência com modificações. A Origem das espécies alcançou um êxito editorial imediato. Darwin reflectiu sobre o surpreendente sucesso da sua obra: 1.250 exemplares esgotados em 24 de Novembro de 1859; mais 3.000 exemplares em 1860, na segunda edição; até 1876, só em Inglaterra, havia 16.000 exemplares vendidos ${ }^{6}$.

${ }^{1}$ Adaptação de um fragmento da obra de Ana Leonor Pereira, Darwin em Portugal. Filosofia. História. Engenharia Social (1865-1914), Coimbra, Almedina, 2001, 629 p.

${ }^{2}$ Charles Darwin, Memorias y epistolario intimo. Mi vida-Recuerdos del hijo - Correspondencia selecta. Prólogo de Alberto Palcos. Buenos Aires, Editorial Elevación, 1946, p. 165 e ss.; vide também Michael Ruse, La revolución darwinista (La ciencia al rojo vivo), Madrid, Alianza Editorial, 1983, pp. 73-82.

3 Vide: James A. Secord, "The discovery of a vocation: Darwin's early geology», The British Journal for the History of Science, London, 24 (2-81) Jun. 1991, pp. 133-157. Frank H. T. Rodhes, "Darwin's search for a theory of the earth; symmetry, simplicity and speculation", The British Jounal for the History of Science, London, 24 (2-81) Jun. 1991, pp. 193-229.

${ }^{4}$ Vide: Michael T. Ghiselin, «Darwin, Charles Robert 1809-1882». In: Dictionnaire du darwinisme et de l'évolution, vol. 1, Paris, Presses Universitaires de France, 1996, sobretudo p. 774.

5 Vide: Sandra Herbert, "Charles Darwin as a prospective geological author», The British Journal for the History of Science, London, 24 (2-81) Jun. 1991, pp. 159-192.

${ }^{6}$ Cf. Charles Darwin, Memorias y epistolario intimo... ob. cit., p. 84. Os números referidos coincidem com os dados da investigação de R. B. Freeman, The works of Charles Darwin. An annotated bibliographical 
$\mathrm{Na}$ teoria darwiniana, as espécies animais e vegetais reproduzem-se tão rápida e abundantemente ${ }^{7}$ que a luta pela vida é inevitável: luta entre indivíduos da mesma espécie, luta entre indivíduos de espécies diferentes e luta com as condições físicas da vida. É o poder de multiplicação das espécies que gera a luta donde resulta a sobrevivência dos mais aptos e a eliminação dos menos aptos, ou seja, a selecção natural das variações vantajosas e consequentemente a evolução adaptativa. A luta é fundamental mas a matéria prima sobre a qual opera a selecção natural é a variação.

Importa ter sempre presente que a obra darwiniana apresentava uma hipótese inovadora, que demorou cerca de vinte $\operatorname{anos}^{8}$ a ser testada e convertida em modelo teórico (1839-1859). Era normal que ela despertasse o interesse da comunidade científica e a curiosidade do público leitor. François Russo admite que nada há de extraordinário no sucesso da obra darwiniana pois uma revolução científica, ou «le saut dans la nouveauté est souvent offert par une publication qui fait sensation» ${ }^{9}$. A Origem das espécies não é uma excepção à regra ${ }^{10}$. Também ela teve um longo tempo de maturação para poder dar "o salto na novidade» de que fala François Russo. Darwin contava trinta anos quando começou a conceber a teoria da descendência com modificações por selecção natural. Aos cinquenta anos de idade dá à estampa a sua obra magna que se difundiu por todo o mundo em onze línguas até à morte de Darwin em 1882, e num total de vinte e nove línguas até $1977^{11}$. Nenhuma outra obra de Darwin alcançou semelhante êxito. A Origem do homem (1871) e A expressão das emoções (1872), obras que desenvolvem o «longo argumento» de $1859^{12}$, particularmente em relação à espécie humana, ficaram um pouco aquém da Origem das espécies, conforme se pode verificar nos quadros seguintes.

handlist. Second edition revised and enlarged. Folkestone-Hamden, Dawson-Archon Books, 1977, pp. 84-87. Comparando com as tiragens de algumas obras literárias, os números referidos não são muito elevados. Mas, tratando-se de uma obra científica, a tiragem foi, de facto, excepcional. Vide: Gertrude Himmelfarb, Darwin and the darwinian revolution, London, Chatto \& Windus, 1959, p. 209.

${ }^{7}$ No impressivo texto darwiniano: «all organic beings, without exception, tend to increase at so high a ratio, that no district, no station, not even the whole surface of the land or the whole ocean, would hold the progeny of a single pair after a certain number of generations», Idem, ibidem, vol. 1, pp. 5-6.

${ }^{8}$ Vinte anos é o tempo médio de maturação das grandes obras científicas e filosóficas. Vide: Paul Scheurer, Révolutions de la science et permanence du réel, Paris, PUF, 1979, sobretudo p. 7.

${ }^{9}$ François Russo, Nature et méthode de l'histoire de sciences, Paris, Librairie Scientifique et Technique Albert Blanchard, 1983, p. 99.

${ }^{10} \mathrm{Na}$ história das ciências, algumas obras são marcos de viragem, sinalizam a emergência de novos paradigmas: "par exemple la publication des 'Principia' de Newton en 1687, de l' 'Origine des espèces' en 1859 par Darwin, de la Communication à l'Académie de Berlin en Décembre 1900 de Planck qui introduisait la notion de quanta, du mémoire d'Einstein en 1905 sur la relativité», François Russo, Nature et méthode de l'histoire de sciences, ob. cit., p. 99.

${ }^{11}$ Vide: R. B. Freeman, The works of Charles Darwin. An annotated bibliographical handlist, Second edition revised and enlarged. Folkestone-Hamden, Dawson-Archon Books, 1977, p. 83.

12 Vide: Charles Darwin, The descent of man, and selection in relation to sex, London, John Murray, 1875, pp. 1-4; Idem, The expression of the emotions in man and animals. With a preface by Konrad Lorenz. Chicago-London, The University of Chicago Press, 1965, sobretudo, pp. 347-366. 
Quadro comparativo das diferentes línguas em que foi impressa a obra de Charles Darwin Origem das Espécies e datas das primeiras edições.

\begin{tabular}{|c|c|c|c|c|}
\hline \multicolumn{5}{|c|}{ Origem das Espécies } \\
\hline $\begin{array}{l}\text { Língua de } \\
\text { impressão }\end{array}$ & $\begin{array}{c}\text { Data } \\
\text { da } 1^{\mathrm{a}} \text { ediçãao }\end{array}$ & $\begin{array}{l}\text { No de edições } \\
\text { (até 1913) }\end{array}$ & $\begin{array}{l}\text { No de edições } \\
\text { (até 1920) }\end{array}$ & $\begin{array}{c}\text { No de edições } \\
\text { (até 1977) }\end{array}$ \\
\hline Inglês & 1859 & 148 & 157 & 260 \\
\hline Alemão & 1860 & 20 & 23 & 26 \\
\hline Francês & 1862 & 14 & 14 & 17 \\
\hline Russo & 1864 & 10 & 10 & 18 \\
\hline Italiano & 1864 & 2 & 5 & 12 \\
\hline Holandês & 1864 & 5 & 5 & 6 \\
\hline Sueco & 1869 & 2 & 3 & 3 \\
\hline Dinamarquês & 1872 & 3 & 3 & 5 \\
\hline Polaco & 1873 & 2 & 2 & 4 \\
\hline Húngaro & 1873 & 2 & 2 & 4 \\
\hline Espanhol & 1877 & 6 & 6 & 25 \\
\hline Sérvio & 1878 & 1 & 1 & 2 \\
\hline Japonês & 1896 & 2 & 3 & 15 \\
\hline Chinês & 1903 & 3 & 5 & 8 \\
\hline Português & 1913 & 1 & 1 & 3 \\
\hline Checo & 1914 & - & 1 & 2 \\
\hline Letão & 1914 & - & 1 & 2 \\
\hline Grego & 1915 & - & 1 & 2 \\
\hline Finlandês & 1928 & - & - & 1 \\
\hline Arménio & 1936 & - & - & 2 \\
\hline Ucraniano & 1936 & - & - & 2 \\
\hline Búlgaro & 1946 & - & - & 2 \\
\hline Romeno & 1950 & - & - & 2 \\
\hline Esloveno & 1951 & - & - & 2 \\
\hline Coreano & 1957 & - & - & 4 \\
\hline Lituanio & 1959 & - & - & 1 \\
\hline Hebreu & 1960 & - & - & 2 \\
\hline Hindu & 1964 & - & - & 1 \\
\hline Turco & 1970 & - & - & 1 \\
\hline
\end{tabular}

Quadro construído a partir dos dados colhidos em R. B. Freeman, The works of Charles Darwin. An annotated bibliographical handlist, Second edition revised and enlarged. Folkestone-Hamden, Dawson-Archon Books, 1977, pp. 73-111.

Nota: Em 1913 é publicada a primeira tradução portuguesa da Origem das Espécies. 
Em 2005 é dada à estampa uma nova edição de A Origem das Espécies ${ }^{13}$ Vejamos agora o seguinte quadro:

Quadro comparativo das diferentes línguas em que foi impressa a obra de Charles Darwin Origem do Homem e datas das primeiras edições

\begin{tabular}{|c|c|c|c|c|}
\hline \multicolumn{5}{|c|}{ Origem do Homem } \\
\hline $\begin{array}{l}\text { Língua de } \\
\text { impressão }\end{array}$ & $\begin{array}{c}\text { Data } \\
\text { da } 1^{\mathbf{a}} \text { edição }\end{array}$ & $\begin{array}{c}\text { No de edições } \\
\text { (até 1910) }\end{array}$ & $\begin{array}{c}\text { No de edições } \\
\text { (até 1920) }\end{array}$ & $\begin{array}{c}\text { No de edições } \\
\text { (até 1977) }\end{array}$ \\
\hline Inglês & 1871 & 81 & 91 & 111 \\
\hline Alemão & 1871 & 11 & 13 & 19 \\
\hline Russo & 1871 & 12 & 12 & 15 \\
\hline Italiano & 1871 & 2 & 5 & 13 \\
\hline Holandês & 1871 & 5 & 5 & 5 \\
\hline Francês & 1872 & 7 & 7 & 7 \\
\hline Sueco & 1872 & 1 & 1 & 1 \\
\hline Dinamarquês & 1874 & 2 & 2 & 3 \\
\hline Polaco & 1874 & 1 & 1 & 3 \\
\hline Húngaro & 1884 & 1 & 2 & 5 \\
\hline Espanhol & 1885 & 2 & 2 & 13 \\
\hline Checo & 1906 & 1 & 1 & 2 \\
\hline Português & 1910 & 2 & 3 & 4 \\
\hline Yiddish((judeu-al.) & 1921 & - & - & 3 \\
\hline Búlgaro & 1927 & - & - & 1 \\
\hline Japonês & 1949 & - & - & 1 \\
\hline Esloveno & 1950 & - & - & 1 \\
\hline Romeno & 1967 & - & - & 1 \\
\hline Turco & 1970 & - & - & 1 \\
\hline
\end{tabular}

Yiddish (judeu-al.) - judeu alemão.

Quadro construído a partir dos dados colhidos em R.B. Freeman, The works of Charles Darwin. An annotated bibliographical handlist, Second edition revised and enlarged. Folkestone-Hamden, Dawson-Archon Books, 1977, pp. 128-142.

Nota: Pela primeira vez, em 1910, são publicadas duas traduçóes diferentes, e ambas parciais, em língua portuguesa da Origem do Homem ${ }^{14}$.

13 Vide: Ana Catarina Loureiro, recensão crítica de Charles Darwin, "A Origem das Espécies», Tradução de Dora Baptista, Mem Martins, Publicações Europa-América, 2005, 387 p., Estudos do Século XX, 6, 2006, pp. 404-408.

${ }^{14}$ Charles Darwin, A origem do homem. Traducção synthetisada de João Corrêa d'Oliveira. Porto, Magalhães \& Moniz-Editores, $1910($ ?), 262 pp. - Bibliotheca de Educação Intellectual, 5. ; Charles Darwin, A origem do homem. A selecção natural e a sexual. Traducção de Oldemiro Cesar. Porto, J. Ferreira dos Santos-Editor, 1910, 2 vols. (96 pp. ; 119 pp.). 
Passemos, então, ao quadro seguinte:

Quadro comparativo das diferentes línguas em que foi impressa a obra de

Charles Darwin A Expressão das Emoções e datas das primeiras edições

\begin{tabular}{|l|c|c|c|}
\hline \multicolumn{5}{|c|}{$\begin{array}{c}\text { Língua de } \\
\text { impressão }\end{array}$} & $\begin{array}{c}\text { Data } \\
\text { da 1a edição }\end{array}$ & $\begin{array}{c}\text { No de edição } \\
\text { (até 1920) }\end{array}$ & $\begin{array}{c}\text { No de edição } \\
\text { (até 1977) }\end{array}$ \\
\hline Inglês & 1872 & 24 & 40 \\
\hline Alemão & 1872 & 10 & 12 \\
\hline Russo & 1872 & 6 & 8 \\
\hline Holandês & 1873 & 2 & 2 \\
\hline Polaco & 1873 & 1 & 2 \\
\hline Francês & 1874 & 3 & 3 \\
\hline Italiano & 1878 & 3 & 4 \\
\hline Espanhol & 1902 & 1 & 2 \\
\hline Húngaro & 1963 & - & 1 \\
\hline Checo & 1964 & - & 1 \\
\hline Romeno & 1967 & - & 1 \\
\hline
\end{tabular}

(Quadro construído a partir dos dados colhidos em R.B. Freeman, The works of Charles Darwin. An annotated bibliographical handlist, Second edition revised and enlarged. Folkestone-Hamden, Dawson-Archon Books, 1977, pp. 142-149).

Nota: Recentemente surgiu uma tradução de $A$ Expressão das Emoçôes em língua portuguesa ${ }^{15}$.

No domínio das ciências naturais, a teoria darwiniana conheceu, entre nós, dificuldades de implantação, em larga medida porque a botânica e a zoologia portuguesas encontravam-se na fase de inventariação, descrição, identificação e classificação das espécies, segundo os moldes estáticos de Lineu e de Cuvier e, portanto, à margem dos problemas genealógicos (origens, afinidades, filiação, etc.) do código evolucionista ${ }^{16}$.

${ }^{15}$ Charles Darwin, A Expressão das Emoçôes no Homem e nos Animais, Tradução de José Miguel Silva, Lisboa, Relógio d'Água Editores, 2006, 347 p.

${ }^{16}$ Vide: Ana Leonor Pereira; João Rui Pita, "Ciências». In: História de Portugal. Direcção de José Mattoso. vol. 5 - O liberalismo (1807-1890). Coordenação de Luís Reis Torgal e João Lourenço Roque, Lisboa, Círculo de Leitores, 1993, pp. 656-658. Sobre o estado da história natural, entre nós, por volta de 1880 e de 1890, vide, respectivamente: A. J. Ferreira da Silva, «Exposição de historia natural. Discurso d'abertura do Presidente da Secção de Sciencias Physiologico-Naturaes, pronunciado no dia 16 de Outubro", Revista da Sociedade de Instrucção do Porto, Porto, 1 (11) 1 Nov. 1881, pp. 343-357; Júlio Augusto Henriques, "Universidade de Coimbra. Faculdade de Philosophia. 1879-1892», O Instituto, Coimbra, 41 (1) Jul. 1893, pp. 29-49. 
No entanto, é justo reconhecer que a defesa consistente da teoria biológica de Darwin foi inaugurada por Júlio Augusto Henriques em 1865, na sua dissertação para o acto de conclusōes magnas, apresentada à Faculdade de Filosofia da Universidade de Coimbra ${ }^{17}$. Em 1866, na sua dissertação de concurso para a mesma Faculdade ${ }^{18}$, Júlio Augusto Henriques, antecipando-se em cinco anos ao naturalista inglês, aplica a teoria da evolução por selecção natural à espécie humana. Nestes dois trabalhos excepcionais, o futuro director do Jardim Botânico analisa todas as provas da teoria darwiniana: as provas geológicas, paleontológicas e biogeográficas, as provas da anatomia comparada, da morfologia e da embriologia disponíveis na época; as ilações tiradas da selecção artificial e do hibridismo, etc.. Também revela que inteligiu fielmente a ideia darwiniana de evolução, não a confundindo com a ideia de progresso necessário e teleológico, nem vendo no seu mecanismo - a selecção natural — algum demiurgo com intentos pré-determinados. Na sua Antiguidade do homem (1866), escreve: «Nenhum acontecimento notável, nenhuma circunstância extraordinária acompanhou a aparição do homem. Já a maior parte da flora actual existia, bem como muitos dos animais, que hoje se conhecem. Não foi necessária nenhuma dessas grandes revoluções que a geologia imagina. No decorrer do tempo, num momento da vida da terra, apareceu ele como milhares de seres que o tinham precedido, para talvez desaparecer, como desapareceram muitos animais seus contemporâneos nos primeiros tempos, e como muitos que hoje vão desaparecendo» ${ }^{19}$. O homem é um ser vivo entre os demais seres vivos, animais ou plantas, e, como eles, não tem algum «destino», mas uma existência precária ameaçada por múltiplas contingências.

Pioneiro foi também Jaime Batalha Reis que, em $1866^{20}$, sustentou a doutrina darwiniana da descendência com modificações, embora de forma hábil e superficial, nas suas teses manuscritas apresentadas ao, então, Instituto Geral de Agricultura.

${ }^{17}$ Vide: Júlio Augusto Henriques, As espécies são mudáveis?, Coimbra, Imprensa da Universidade, 1865; Abílio Fernandes, "História da Botânica em Portugal até finais do século XIX». In: História e Desenvolvimento da Ciência em Portugal. I Colóquio - até ao século XX, Lisboa, Academia das Ciências de Lisboa, 1986, vol. 2, sobretudo pp. 234-235.

${ }^{18}$ Vide: Júlio Augusto Henriques, Antiguidade do homem, Coimbra, Imprensa da Universidade, 1866; Ana Leonor Pereira, "O espírito científico contemporâneo na Universidade de Coimbra. Júlio Augusto Henriques». In: Universidade(s) - História. Memória. Perspectivas. Actas do Congresso "História da Universidade» (No $7^{\circ}$ Centenário da sua fundação), Coimbra, Comissão Organizadora do Congresso "História da Universidade», 1991, vol. 1, pp. 347-365.

${ }^{19}$ Júlio Augusto Henriques, Antiguidade do homem, ob. cit., p. 27.

${ }^{20}$ Vide: Jaime Batalha Reis, A vinha e o vinho. Dissertação e theses, apresentadas ao Instituto Geral de Agricultura, para serem sustentadas no acto final do Curso de Agronomia. Lisboa, 1866 (Manuscrito - Instituto Superior de Agronomia, Lisboa). Vide, também, na Biblioteca Nacional de Lisboa, Espólio Jaime Batalha Reis, Esp. 4, Caixa 45, pasta 78. Carta de Jaime Batalha Reis a Pedro Batalha Reis, seu sobrinho, datada de 9 de Outubro de 1930 (Manuscrito). Vide, também, o artigo de João Carlos Garcia, "Jaime Batalha Reis, geógrafo esquecido», Finisterra, Lisboa, 20 (40), 1985, pp. 300-314. Em 1871, Jaime Batalha Reis invoca a autoridade de Darwin para condenar a proibição das Conferências Democráticas do Casino Lisbonense. Vide: Jaime Batalha Reis, «Eu sou socialista». In: João Medina, As conferências do Casino e o socialismo em Portugal, Lisboa, Publicaçōes Dom Quixote, 1894, pp. 86-90. Trata-se de um excerto da "Carta ao Ex ${ }^{\text {mo. }}$ Sr. Marquês de Ávila e Bolama, Porto, Tipografia Comercial, Belmonte, 1871, 12 p.». Em 1894 e 1895 Jaime Batalha Reis inaugurou os estudos de geografia científica em Portugal, com os seguintes trabalhos: "As leis naturais do mundo. O organismo-terra" (artigo publicado em O Comércio do Porto, 20 Jan. 1894); 
Por outro lado, tanto quanto pudemos averiguar, foi precisamente um jovem naturalista, auto-didacta e adepto convicto da teoria darwiniana, Arruda Furtado, o único português a travar correspondência com Charles Darwin ${ }^{21}$. O sábio inglês, então, com setenta e dois anos, propusera ao jovem açoreano um plano de estudos da fauna e da flora do arquipélago dos Açores. Morto prematuramente de tuberculose, com 33 anos, em 1887, Francisco de Arruda Furtado ainda publicou vários artigos sobre malacologia açoriana ${ }^{22}$ e deixou um manuscrito intitulado "Programa de explorações malacológicas nos mares dos Açores» que, até hoje, não foi cumprido ${ }^{23}$.

Outros cientistas da natureza ${ }^{24}$ pronunciaram-se sobre o darwinismo, enquanto teoria da evolução orgânica, sendo justo salientar o bem informado trabalho manuscrito do naturalista botânico, Luís Wittnich Carrisso ${ }^{25}$, datado de 1910, o compêndio de Bernardo Aires de $1911^{26}$, e o qualificado estudo de Armando Cortesão, A teoria da mutação e o melhoramento das plantas: (Estudo trematológico), publicado em $1913^{27}$.

Nos domínios da paleoantropologia e da arqueologia pré-histórica em Portugal, 1865 é uma data memorável pois, nesse ano, Pereira da Costa publica um estudo pioneiro $^{28}$, ao qual se seguiram outros trabalhos do mesmo autor ${ }^{29}$, bem como de

"On the definition of Geography as a science and on the conception and description of the earth as an organism» (apresentado no Sixth International Geographical Congress, London, 1895). Artigos reproduzidos em, Jaime Batalha Reis, Estudos geográficos e históricos, Lisboa, Agência Geral das Colónias, 1941, respectivamente, pp. 147-168; pp. 169-195.

${ }^{21}$ Vide: Carlos das Neves Tavares, "Quatro cartas inéditas de Charles Darwin para Francisco d'Arruda Furtado", Revista da Faculdade de Ciências da Universidade de Lisboa, 2a sér., C - Ciências Naturais, Lisboa, 5 (2), 1957, pp. 277-305; Germano da Fonseca Sacarrão, «Sobre o método em Darwin e a episódica relação com Arruda Furtado", Prelo, Lisboa, (11), Abr. Jun. 1986, pp. 81-88; Manuel Cadafaz de Matos, «Arruda Furtado correspondente de Darwin», Prelo, Lisboa, (11) Abr.-Jun. 1986, pp. 89-93.

22 Vide, por exemplo: Arruda Furtado, «Pequenas contribuiçōes para o estudo da origem das especies malacologicas terrestres das ilhas dos Açores», Era Nova, Lisboa, 1, 1880-1881, pp. 548-552.

${ }^{23}$ Vide: António M. de Frias Martins, «Arruda Furtado na malacologia açoriana», Açoreana, Ponta Delgada, 7 (1), 1989, pp. 9-16.

${ }^{24}$ Nomeadamente, Albino Augusto Giraldes, Questôes de philosophia natural (Notas e apontamentos): II - O darwinismo ou a origem das especies. Conferencia, Coimbra, Imprensa da Universidade, 1878; João Gualberto de Barros e Cunha, As ultimas theorias biologicas, Coimbra, Imprensa da Universidade, 1892.

25 Vide: Luís Wittnich Carrisso, Hereditariedade. Coimbra, Edição do A., 1910. [3], 236 fl. - Dissertação manuscrita para o acto de licenciatura na Secção de Sciencias Historico-Naturais da Faculdade de Philosophia, apresentada em 14 de Março de 1910 (Biblioteca Geral da Universidade de Coimbra).

${ }^{26}$ Vide: Bernardo Aires, Principios de biologia. Protozoarios, Coimbra, Imprensa da Universidade, 1911, sobretudo pp. 312-377. Em 1892, defendia nas suas teses: «Botânica I - Sustentamos a identidade filogenética dos vegetais e animais»; «Zoologia II - Negamos a hereditariedade das mutilaçôes(Weismann)», Bernardo Aires, Theses de philosophia natural que (...) se propöe defender na Universidade de Coimbra nos dias 22 e 23 de Junho de 1892 para obter o grau de doutor, Coimbra, Imprensa da Universidade, 1892, p. 17.

${ }^{27}$ Armando Cortesão, A teoria da mutação e o melhoramento das plantas: (Estudo trematológico). Porto, «Renascença Portuguesa», 1913.

${ }^{28}$ Vide: F. A. Pereira da Costa, Da existência do homem em epochas remotas no valle do Tejo. Primeiro opusculo. Noticia sobre os esqueletos humanos descobertos no cabeço da Arruda, Lisboa, Imprensa Nacional, 1865 (com uma versão em francês).

${ }^{29}$ Vide: F. A. Pereira da Costa, Noçôes sobre o estado prehistorico da terra e do homem seguidas da descripção de alguns dolmins ou antas de Portugal. Com a traducçẫo franceza de M. Dalhunty. Lisboa, Typographia da Academia Real das Sciencias, 1868. 
Nery Delgado e de Carlos Ribeiro, realizados no âmbito da Segunda Comissão Geológica de Portuga ${ }^{\beta 0}$. Com efeito, os trabalhos de prospecção e levantamento geológico do país estão directamente ligados ao nascimento daquelas disciplinas científicas entre nós. A paixão pela descoberta de restos humanos fósseis e de outros vestígios da sua existência em depósitos antigos da era quaternária da terra, foi concretizada por Carlos Ribeiro para lá das expectativas mais serenas. Convicto de que um conjunto de peças líticas, que encontrou em camadas da era terciária nos vales do Tejo e do Sado, constituíam uma prova da altíssima antiguidade do homem, lançou-as para o debate internacional, entre 1871 e $1880^{31}$ e conseguiu que o IX Congresso Internacional de Antropologia e de Arqueologia Pré-Histórica tivesse lugar em Lisboa, no ano de 1880. Calorosamente defendeu que aqueles «eólitos» tinham sido talhados intencionalmente por um ser muito antigo, de baixa estatura ${ }^{32}$. O sábio antropo-arqueólogo Gabriel de Mortillet, impressionado, precipitou-se e baptizou esse hipotético homem-macaco, do qual «nem um dente se conhece» ${ }^{33}$, com o nome de "Homo simius Ribeiro» ou "anthropopithecus Ribeiro» ${ }^{34}$. Vários estudiosos internacionais e nacionais mostraram

30 Vide: Paul Choffat, "La géologie portugaise et l'oeuvre de Nery Delgado», Bulletin de la Société Portugaise des Sciences Naturelles, Lisbonne, 3, supl. 1, 1909, sobretudo pp. 15-33; M. Teles Antunes, «Sobre a história da paleontologia em Portugal». In: História e Desenvolvimento da Ciência em Portugal. I Colóquio - até ao século XX. Lisboa, Academia das Ciências de Lisboa, 1986, vol. 2, sobretudo, p. 793 e ss.

${ }^{31}$ Vide: Carlos Ribeiro, Relatorio ácerca da sexta reunião do Congresso de Anthropologia e de Archeologia Prehistorica verificada na cidade de Bruxellas em Agosto de 1872, Lisboa, Imprensa Nacional, 1873, pp. 7-8; Gabriel Mortillet; Adrien de Mortillet, Musée préhistorique. Album de 105 planches. Photogravure C. Ruckert. Deuxième édition revue et complétée. Paris, Librairie C. Reinwald, 1903, (Planche III). A defesa da existência do «homem terciário» não representava uma ousadia pessoal de Carlos Ribeiro. Entre outros, pronunciaram-se a favor desta hipótese, Correia Barata: «Sustentamos a existência do homem terciário (mioceno, plioceno)", Theses de philosophia natural que (...) se propóe defender na Universidade de Coimbra para obter o grau de doutor, Coimbra, Imprensa da Universidade, 1872, p. 15; José Diogo Arroio: «Foi durante o período terciário que a evolução duma forma pitecóide superior produziu o homem», Theses de philosophia natural que (...) se propóe defender na Universidade de Coimbra para obter o grau de doutor, Coimbra, Imprensa da Universidade, 1880, p. 19; Bernardo Aires: «O homem terciário existiu no Ocidente da Europa", Theses de philosophia natural que (...) se propõe defender na Universidade de Coimbra nos dias 22 e 23 de Junho de 1892 para obter o grau de doutor, Coimbra, Imprensa da Universidade, 1892, p. 21. Sublinhado do Autor. Também o professor da Faculdade de Direito da Universidade de Coimbra, João José Mendonça Cortez, em 1876, admitia a existência do "homem terciário». Vide: Códice 9759, Estudos geológicos e antropológicos da Península Ibérica. Documentos autógrafos do A. 4 maços. Maço 1. Manuscritos existentes na B.N.L..

32 Vide: Carlos Ribeiro, «L'homme tertiaire en Portugal». In: Congrès International d'Anthropologie et d'Archéologie Préhistoriques - Compte rendu, Lisbonne, Typographie de l'Académie Royale des Sciences 1884, pp. 81-92.

33 Mendes Correia, Homo: (Os modernos estudos sobre a origem do homem). 2a edição inteiramente refundida, Coimbra, "Atlantida» Livraria Editora, 1926, p. 131.

${ }^{34}$ Vide: Ricardo Severo, "Carlos Ribeiro", Revista de Sciencias Naturaes e Sociaes, Porto, 5, 1898, pp. 169-170; Ricardo Jorge, Hygiene social applicada á Nação Portugueza. Conferencias feitas no Porto, Porto, Livraria Civilisação de Eduardo da Costa Santos-Editor, 1885, p. 93. Vide, também: Alexandre da Conceição, "O sr. Carlos Ribeiro e a questão do homem terciario», O Seculo, Lisboa, 2 (592) 14 Dez. 1882, p. 1; António Augusto Mendes Correia, "O homem terciário em Portugal», Lusitania, Lisboa, 3(9) 1926, pp. 1-16; António Carlos Silva, "A questão do 'homem terciário’ portugûes», História, Lisboa, (21) Jul. 1980, pp. 50-60. 
reservas quanto às provas da existência do referido homem terciário, nomeadamente, Nery Delgado ${ }^{35}$, mas nenhuma escrita gravou um juízo mais certeiro daquelas ciências tão novas e tão ávidas de dogmas e de $\operatorname{mitos}^{36}$, como o traço firme e sugestivo de Rafael Bordalo Pinheiro ${ }^{37}$.

A relação entre a paleoantropologia, a pré-história e o darwinismo não é uma evidência ${ }^{38}$ nos trabalhos de campo dos cultores portugueses das referidas disciplinas. Mas, dado que o seu referente teórico fundamental era a obra de Charles Lyell, sobretudo, The geological evidences of the antiquity of man $(1863)^{39}$, traduzida para francês em 1864, na qual o geólogo escocês expunha a teoria de Darwin e aplicava-a à espécie humana ${ }^{40}$, é lícito afirmar que, pelo menos, indirectamente, a revolução darwiniana repercutiu-se nas pesquisas de campo paleoantropológicas em Portugal.

De grande alcance, embora não directamente em termos de impacto darwínico, foi a criação da cadeira de «Antropologia, Paleontologia Humana e Arqueologia Pré-histórica» em 1885, por Bernardino Machado, na Faculdade de Filosofia da Universidade de Coimbra ${ }^{41}$. É certo que Bernardino Machado não invoca a autoridade de Darwin para justificar a necessidade de institucionalização dos estudos antropológicos ${ }^{42} \mathrm{e}$ que as obras darwinianas de 1859, 1871 e de 1872 não constam na lista dos manuais que recomendou aos alunos ${ }^{43}$. Está igualmente provado que, sob a orientação de Bernardino Machado, os alunos dedicavam-se sobretudo à antropologia física, tendo elaborado trabalhos de craniometria e de osteometria desde $1885^{44}$. No entanto, o

\footnotetext{
${ }^{35}$ Vide: Joaquim Filipe Nery Delgado, Relatorio ácerca da decima sessão do Congresso Internacional de Anthropologia e Archeologia Prehistoricas, Lisboa, Imprensa Nacional, 1890, pp. 33-35.

${ }^{36}$ Vide: Hermann Schaaffhausen, «L'homme préhistorique». In: Congrès International d'Anthropologie et d'Archéologie Préhistoriques - Compte rendu., Lisbonne, Typographie de l'Académie Royale des Sciences 1884, pp. 140-150.

37 Vide: Rafael Bordalo Pinheiro, «Abertura dos congressos» [e seguintes], O Antonio Maria, Lisboa, 2 (69) 23 de Setembro de 1880, pp. 309-316; 2 (70) 30 de Setembro de 1880, pp. 317-324.

${ }^{38}$ Sobre esta temática a nível europeu, vide: Claude Masset, «Darwinisme et préhistoire?». In: Darwinisme et société. Direction de Patrick Tort, Paris, Presses Universitaires de France, 1992, pp. 651-655; Bruce G. Trigger, A history of archaeological thought, Cambridge e outras, Cambridge University Press, 1989.

39 Vide: F.A. Pereira da Costa, Da existência do homem em epochas remotas no valle do Tejo. Primeiro opusculo. Noticia sobre os esqueletos humanos descobertos no cabeço da Arruda, Lisboa, Imprensa Nacional, 1865 , p. 3.

${ }^{40}$ Vide: Charles Lyell, L'ancienneté de l’homme prouvée par la géologie et remarques sur les théories relatives a l'origine des espèces par variation. Traduit avec le consentement et le concours de l'auteur par Mr. M. Chaper. Deuxième édition. Paris, J. - B. Baillière et Fils, 1870, pp. 451-559.

${ }^{41}$ Vide: Cem anos de antropologia em Coimbra 1885-1985, Coimbra, Museu e Laboratório Antropológico, 1985, p. 13 e ss. Vide também, Manuel Laranjeira Rodrigues Areia; M. A. Tavares da Rocha; M. Arminda Miranda, "O Museu e Laboratório Antropológico da Universidade de Coimbra». In: Universidade(s) Historia. Memória. Perspectivas. Actas do Congresso "História da Universidade» (No $7^{\circ}$ Centenário da sua fundação), ob. cit., vol. 2, pp. 87-105.

42 Vide: Bernardino Machado, A Universidade de Coimbra. Segunda edição. Lisboa, Ed. do A., 1908, pp. $45-49$

43 Vide: Cem anos de antropologia em Coimbra 1885-1985, ob. cit., p. 15.

${ }^{44}$ Vide: Aula de Antropologia da Universidade de Coimbra - Trabalhos de alumnos, Coimbra, Imprensa da Universidade, 1902. Compreende doze estudos antropométricos (índice cefálico, índice nasal dos
} 
sábio professor e político tinha defendido em 1876, nas suas Theses de philosophia, a seguinte proposição: «a variabilidade e a hereditariedade, nas condições de luta para a existência, produzem a selecção natural» ${ }^{45}$. E mesmo que este enunciado (defendido na Secção de "Zoologia e Geologia») não seja propriamente darwínico, pois falta nele algo de essencial, a saber, a descendência com modificações ou evolução, julgamos que Bernardino Machado não foi indiferente à revolução darwiniana. Para provar isto mesmo, transcrevemos as palavras que dedicou à memória do naturalista inglês, curiosamente num discurso comemorativo do centenário da morte do Marquês de Pombal, onde se lê: «um Darwin, por exemplo. Se lidou esse! lidou constantemente; e assim, alento a alento, tirou de si a obra assombrosa da teoria das transformaçóes orgânicas, ou, como para lhe perpetuar o nome melhor se diz, o darwinismo: tirou-o de si a poder do engenho e com a paciência com que o oceano - explicou ele — floreja à superfície os colossais recifes coralinos feitos de animalculos quase invisíveis. Para sempre seja bendita a tua memória, adorável sábio!» ${ }^{46}$. Embora não tenha escrito algum tratado, não duvidamos que Bernardino Machado e os seus sucessores estavam perfeitamente ao corrente da antropologia darwínica mais ou menos ortodoxa. Tenhamos sempre presente que Júlio Augusto Henriques abriu o caminho aos seus discípulos, o que, a par do interesse de cada um pelo novo, permite-nos admitir que teses como as de Meireles Garrido ${ }^{47}$ ou de Silva Basto ${ }^{48}$ não eram excepções.

Quem, na verdade, fora de qualquer enquadramento institucional, escreveu o primeiro tratado de Antropologia evolucionista foi Oliveira Martins que se revelou um tratadista genial, porque simultaneamente expositivo e crítico. A primeira edição dos seus Elementos de antropologia foi publicada em $1880^{49}$, no ano em que decorreu o IX Congresso Internacional de Antropologia e de Arqueologia Pré-histórica, em Lisboa. Igualmente em 1880 começa a ser estampada a História natural illustrada de Júlio de

portugueses, etc.) feitos pelos alunos: João Gualberto de Barros e Cunha, Álvaro José da Silva Basto, José Cardoso de Meneses, António Aurélio da Costa Ferreira, João Salema, Alexandre Alberto de Sousa Pinto, Agostinho Viegas da Cunha Lucas, João Ernesto Mascarenhas de Melo, Vasco Nogueira de Oliveira, Abílio Augusto da Silva Barreiro, Álvaro R. Machado. Por outro lado, dos nove trabalhos manuscritos, existentes no Cofre do Departamento de Antropologia da Universidade de Coimbra, apresentados entre 1897 e 1907 , cinco abordam temas de antropologia física e apenas um reflecte a influência do evolucionismo mais lamarckista do que darwiniano. É o trabalho de José de Oliveira Ferreira Dinis, devidamente referenciado na nossa Bibliografia, tal como os restantes.

${ }^{45}$ Bernardino Machado, Theses de philosophia natural que (...) se propõe defender na Universidade de Coimbra no dia 9 de Junho de 1876 para obter o grau de doutor, Coimbra, Imprensa da Universidade, 1876, p. 13.

${ }^{46}$ Bernardino Machado, Discurso commemorativo do Marquez de Pombal, Coimbra, Imprensa da Universidade, 1882, p. 6.

47 "o darwinismo explica a origem natural do homem», António de Meireles Garrido, Theses de philosophia natural que (...) se propóe defender na Universidade de Coimbra no dia 8 de Junho de 1878 para obter o grau de doutor, Coimbra, Imprensa da Universidade, 1878, p. 15. Sublinhado do Autor.

48 "Consideramos o Pithecanthropus erectus de Dubois como o precursor do homem», Álvaro José da Silva Basto, Theses de philosophia natural que (...) se propõe defender na Universidade de Coimbra, nos dias 9 e 10 de Julho de 1897, para obter o grau de doutor, Coimbra, Imprensa da Universidade, 1897, p. 17. Sublinhado do Autor.

${ }^{49}$ Vide: Oliveira Martins, Elementos de antropologia: (Historia natural do homem), Lisboa, Livraria Bertrand, 1880. 
$\operatorname{Matos}^{50}$, uma das obras em que o autor se afirma como um dos representantes mais completos e genuínos do darwinismo em Portugal.

A cultura portuguesa não podia passar ao lado de "uma teoria tão poderosa como a de Darwin" "51, mas foi, sobretudo, enquanto teoria antropo-histórica e social que ela se reflectiu entre nós. As duas últimas partes da nossa dissertação destinam-se, precisamente, a provar este enunciado.

Tem algum significado o facto da obra darwiniana de 1871 ter sido traduzida antes da obra capital de 1859. A tradução da primeira foi publicada em $1910^{52}$ e a da segunda em $1913^{53}$. Tardiamente, sem dúvida, mas não esqueçamos o "francesismo» $\$ 4$ português da época que dispunha das primeiras traduções francesas das obras de 1859 e de 1871 , desde 1862 e de 1872 , respectivamente ${ }^{55}$. À volta de 1910 , houve um surto de pequenos artigos e notícias de difusão do darwinismo antropo-histórico para o grande público ${ }^{56}$.

50 Júlio de Matos, Historia natural illustrada. Compilação feita sobre os mais auctorisados trabalhos zoologicos, Porto, Livraria Universal, [1880-1882], 6 vols..

${ }^{51}$ François Jacob, O jogo dos possiveis. Ensaio sobre a diversidade do mundo vivo, Lisboa, Gradiva, 1985, p. 49.

52 Vide: Charles Darwin, A origem do homem. A selecção natural e a sexual. Traducção de Oldemiro Cesar [jornalista, tradutor]. Porto, J. Ferreira dos Santos-Editor, 1910, 2 vols.; Idem, A origem do homem. Traducção synthetisada de João Corrêa d'Oliveira [escritor e tradutor]. Porto, Magalhães \& Moniz-Editores, 1910(?). Nestas duas versões, a segunda parte da obra darwiniana (a selecção sexual) foi completamente omitida. No entanto, em português, o público tinha acesso a longas passagens da segunda parte da obra darwiniana de 1871, num livro de Arruda Furtado, $O$ macho e a femea no reino animal, Lisboa, David Corazzi Editor, 1886. A obra de E. Denoy, Descendemos do macaco? (Trad. Moraes Rosa. Lisboa, Livraria Internacional, 1910) inclui nas pp. 100-139 uma antologia da obra darwiniana de 1871. Um pequeno «extracto de Charles Darwin - A procedencia do homem» foi publicado na rubrica "Variedades», O Zoophilo, Lisboa, 1 (1) 14 Jan. 1877, p. 4.

${ }^{53}$ Vide: Charles Darwin, Origem das espécies. Trad. Joaquim Dá Mesquita Paúl, [médico e professor]. Porto, Livraria Chardron, 1913.

${ }^{54}$ Vide: Eça de Queirós, «O ‘Francezismo’ ». In: Eça de Queirós, Ultimas paginas (Manuscriptos ineditos), Porto-Lisboa, Livraria Lello \& Irmão Editores-Aillaud \& Lellos, s.d., pp. 397-425. No mesmo sentido, vide a dissertação apresentada à Faculdade de Medicina do Porto, por Alberto Ferreira de Lemos, A França como factor principal da Sciencia, Porto, Typographia Artes e Lettras, 1912.

${ }^{55}$ Vide: Yvette Conry, L'introduction du darwinisme en France au XIX ${ }^{e}$ siècle, Paris, Librairie Philosophique J. Vrin, 1974, p. 438.

56 Vide, entre outros: «Origem e patria primitiva da humanidade», «Idade e origem dos homens", Almanach Encyclopedico Illustrado para 1908, Coordenado pelo professor Agostinho Fortes, Lisboa, 1908, respectivamente, pp. 73-79 e pp. 235-246; "O homem do futuro», Almanach Illustrado d'O Seculo, Lisboa, 13, 1909, p. 150; "O correr do cabelo. Curiosidade da raça humana», Almanach Encyclopedico Illustrado para 1909. Coordenado pelo Professor Agostinho Fortes, Lisboa, 1909, pp. 167-169; Cacilda de Castro, "O riso", Illustração Portugueza, Lisboa, 2a sér., 195, 15 Nov. 1909, pp. 623-629; "Estudos da fisionomia e do gesto", Almanach Illustrado d' O Seculo , Lisboa, 13, 1909, p. 114; Lino de Macedo, "A edade humana", Vanguarda, Lisboa, 12 (4516) 6 Ago. 1909, p. 1; Idem, "A edade da terra»,Vanguarda, Lisboa, 12 (4522) 12 Ago. 1909, p. 1; "Os antepassados do homem», Almanach Illustrado d' O Seculo, Lisboa, 14, 1910, pp. 91-95. Anteriormente, merecem especial destaque, pela sua força irónica, os seguintes documentos: Rafael Bordalo Pinheiro, "A teoria de Darwin», Pontos nos ii, Lisboa, 2 (63) 17 Jul. 1886, pp. 500-501. Posteriormente, não podemos omitir, entre outras liçôes darwinistas proferidas no Curso de educação popular da Universidade Livre, a lição de Rui Teles Palhinha, O homem como ser animal, Lisboa, Universidade Livre, 1912. 
Veja-se, por exemplo, este folheto volante ${ }^{57}$ :

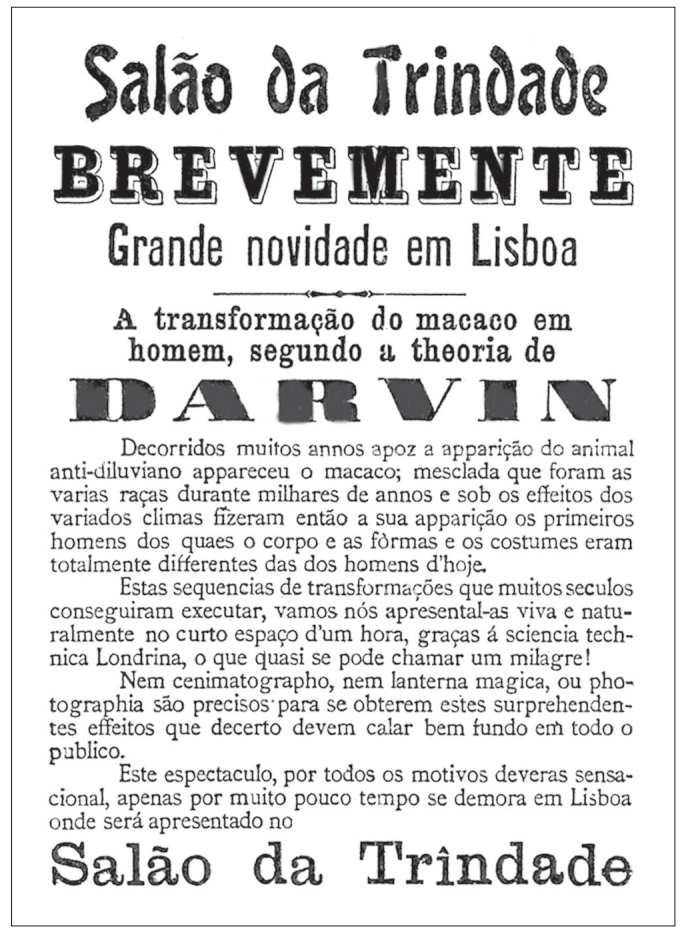

No entanto, deve sublinhar-se que as letras portuguesas, com Teófilo Braga, Oliveira Martins, Eça de Queirós e outros, já tinham assimilado, com originalidade, a revolução darwiniana, claramente, desde finais da década de setenta do século XIX, como já provámos noutro lugar.

Julgamos que tem interesse fazer uma ideia do que foi escrito em Portugal, com o objectivo de prestar homenagem ao naturalista inglês, por ocasião da sua morte em 1882, e para celebrar o cinquentenário da Origem das espécies, em 1909. Saber quem escreveu e o quê, a esses títulos, é um indicativo muito falível dos representantes de Darwin em Portugal. Mas, permite-nos constatar se, também neste registo, foi a dimensão antropo-histórica e social do darwinismo, aquela que mais ecos produziu na cultura portuguesa.

Darwin morre em 19 de Abril de 1882 e foi enterrado na abadia de Westminster em 26 de Abril de $1882^{58}$. Praticamente um mês antes da morte do naturalista inglês,

\footnotetext{
${ }^{57}$ Folheto (Folha) volante na colecção particular do Arquivo da Universidade - Colecção Jardim de Vilhena - A.U.C.-VI-30-1-2-27

${ }^{58}$ Vide: Michael T. Ghiselin, "Charles Robert Darwin 1809-1882». In: Dictionnaire du darwinisme et de l'évolution, vol. 1, ob. cit., pp. 772-798.
} 
Júlio Augusto Henriques, o eminente botânico que em 1866 se antecipara à obra darwiniana de 1871, publica no Porto um artigo intitulado "Carlos Darwin» ${ }^{59}$. Nele, o fundador da Sociedade Broteriana (1879) e do seu Boletim (1882) celebra a vida e a obra do sábio inglês. O retrato de Darwin ilustra a primeira página do artigo.

$\mathrm{Na}$ sua exposição da teoria darwiniana, Júlio Henriques sublinha uma diferença muito importante entre a selecção natural e a selecção artificial praticada pelo horticultor e pelo criador de raças animais. Se esta é intencional, a primeira não tem em vista algum fim preconcebido, apenas significa a sobrevivência dos membros de uma espécie que, na luta pela vida, apresentam as variaçôes mais vantajosas em função do meio. Foi também Júlio Augusto Henriques quem prestou culto à memória de Darwin em $O$ Instituto, tendo, para o efeito, traduzido um notável trabalho do naturalista-botânico francês Alphonse de Candolle ${ }^{60}$.

Em homenagem ao sábio inglês, Teófilo Braga, o grande doutrinador da sociologia positiva, publicou ${ }^{61}$ uma síntese da teoria darwiniana, do darwinismo antropológico de Ernst Hæckel e do darwinismo social de Herbert Spencer, apoiando-se em Th. Huxley ${ }^{62}$ e, curiosamente, não se socorrendo da leitura lamarckisante de Darwin produzida em França, especialmente por Clémence Royer ${ }^{63}$. Nas páginas da revista O Positivismo, a notícia da morte de Darwin foi escrita por Júlio de Matos ${ }^{64}$, mas quem homenageou Darwin foi Arruda Furtado, igualmente discípulo e correspondente ${ }^{65}$ de Teófilo Braga, com um artigo intitulado «Embryologia» 66 .

No referido artigo, o jovem naturalista expunha uma das provas capitais da teoria evolucionista, recorrendo, entre outras obras, à edição definitiva da Origem das espécies, no original inglês. No entanto, uma parte do artigo é reservada para combater a teologia, a metafísica e a religiāo, na sequência do que havia feito no ano anterior ${ }^{67}$.

59 Júlio Augusto Henriques, "Carlos Darwin», Jornal de Horticultura Pratica, Porto, 13 (3) Mar. 1882, pp. 41-44. O mais provável é que o jornal andasse atrasado.

60 Vide: A. de Candolle, "C. Darwin: Causas do successo de seus trabalhos e importancia d'elles». O Instituto, Coimbra, 30 (8) Fev. 1883, pp. 344-364; Júlio Augusto Henriques, "Affonso de Candole», Boletim da Sociedade Broteriana, Coimbra, 11, 1893, pp. 3-6.

${ }^{61}$ Vide: Teófilo Braga, «Carlos Darwin», O Occidente, Lisboa, 5 (123) 21 Maio 1882, p. 118.

${ }^{62}$ Th. Huxley, Les sciences naturelles et les problèmes qu'elles font surgir, Paris, Librairie J. -B. Baillière et Fils, 1877.

${ }^{63}$ Vide: Charles Darwin, De l'origine des espèces par sélection naturelle ou des lois de transformation des êtres organisés. Traduction de Mme Clémence Royer avec préface et notes du traducteur. Nouvelle édition revue d'après l'édition stéréotype anglaise, avec les additions de l'auteur. Paris, Librairie Marpon \& Flammarion, s. d., 4a edição [1882].

${ }^{64}$ Vide: Júlio de Matos, «Carlos Darwin», O Positivismo, Porto, 4, 1882, p. 180.

65 Vide: Francisco de Arruda Furtado, [4 Cartas para Teófilo Braga datadas de 13 de Novembro de 1882; 29 de Dezembro de 1882; 3 de Maio de 1883; 11 de Dezembro de 1883]. In: Teófilo Braga, Quarenta annos de vida litteraria (1860-1900), Lisboa, Typographia Lusitana - Editora Arthur Brandão, 1902, pp. 162-172.

66 Vide: Francisco de Arruda Furtado, «Embryologia», O Positivismo, Porto, 4, 1882, pp. 121-163.

67 Vide: Francisco de Arruda Furtado, O homem e o macaco (uma questão puramente local), Ponta Delgada, s. ed., 1881; Joaquim dos Reis, «[Recensão crítica de] Furtado, Francisco d'Arruda - O homem e o macaco. Ponta Delgada, 1881», Era Nova, Lisboa, 1, 1880-1881, pp. 476-479. 
Foi também Arruda Furtado quem, em 1882, divulgou a vida e a obra de Darwin, nas colunas dos jornais $O$ Século ${ }^{68}$ e $A$ voz do operario ${ }^{69}$. Assumindo-se como um "humilde discípulo» ${ }^{70}$ do sábio naturalista, Arruda Furtado apresenta Darwin como o "Newton da biologia», mas também como o criador de uma filosofia redentora da humanidade, fundada na suposta verdadeira esperança, a esperança científica: «Cristo propôs-se regenerar um ente miserável, decaído do seu primitivo explendor por causa dos seus pecados; Darwin estimula a humanidade na senda dum progresso incessante e partindo, ao contrário, duma origem obscura e bestial. A diferença é profunda» ${ }^{71}$. Que a teoria da descendência com modificações pode consolar o homem, disse-o Darwin com estas palavras: "Man may be excused for feeling some pride at having risen, though not through his own exertions, to the very summit of the organic scale; and the fact of his having thus risen, instead of having been aboriginally placed there, may give him hope for a still higher destiny in the distant future» ${ }^{72}$. No entanto, o naturalista inglês nunca ousou contrapor o darwinismo ao cristianismo, como fez Arruda Furtado.

Igualmente correspondente de Teófilo $\mathrm{Braga}^{73}$ e colaborador em $O$ Positivismo, Augusto Rocha publicou, em 1882, nas páginas da revista que dirigia, Coimbra Médica, um rigoroso artigo ${ }^{74}$ que dá conta dos traços essenciais da vida do sábio inglês, apresenta uma súmula cronológica da sua obra e resume de forma brilhante a teoria da selecção natural. Sem qualquer reserva, afirma que o darwinismo, «sendo já a doutrina dominante» ${ }^{75}$, alcançará o triunfo universal nos domínios das ciências da vida e das ciências do homem, desde a antropologia e a psicologia à sociologia, pela mãos dos numerosos discípulos espalhados por todo o mundo.

A Sociedade de Geografia de Lisboa, por iniciativa de J.V. Barbosa du Bocage, limitou-se a lançar em acta um voto unânime de sentimento pela morte de Darwin e de reconhecimento do valor científico da sua obra científica ${ }^{76}$. Barbosa du Bocage, o fundador do Museu de História Natural da Escola Politécnica de Lisboa em 1859, embora tenha desenvolvido uma obra fundamental no domínio da zoologia descritiva

${ }^{68}$ Vide: Francisco de Arruda Furtado, "Carlos Darwin», O Seculo, Lisboa, 2 (433) 9 Jun. 1882, pp. 1-2; 2 (434) 10 Jun. 1882, p. 1; 2 (435) 11 Jun. 1882, p. 1.

${ }^{69}$ Vide: Francisco de Arruda Furtado, "Á memoria de Charles Darwin», A Voz do Operário, Lisboa, 6 (140) 18 Jun. 1882, pp. 3-4.

${ }^{70}$ Francisco de Arruda Furtado, "Á memoria de Charles Darwin", art. cit., p. 4.

${ }^{71}$ Francisco de Arruda Furtado, "Carlos Darwin», art. cit. 2(433) 9 Jun. 1882, p. 1.

72 Charles Darwin, The descent of man, and selection in relation to sex, London, John Murray, 1875 , p. 619 .

${ }^{73}$ Vide: Augusto Rocha, [Cartas para Teófilo Braga: 30 Mar. 1879; 1 Jul. 1879].In: Teófilo Braga, Quarenta annos de vida litteraria (1860-1900), Lisboa, Typographia Lusitana - Editora Arthur Brandão, 1902, pp. 150-151.

${ }^{74}$ Vide: Augusto Rocha, "Carlos Roberto Darwin», Coimbra Medica, Coimbra, 2 (10) 15 Maio 1882, pp. 161-164.

75 Idem, ibidem, p. 164.

${ }^{76}$ Vide: «[Acta da sessão de 15 de Maio de 1882 durante a qual foi referida a morte de Darwin]», Actas das Sessóes da Sociedade de Geografia de Lisboa, Lisboa, 2, 1882, pp. 31-50. 
e sistemática e da geografia zoológica ${ }^{77}$ não foi um representante da teoria darwiniana em Portugal ${ }^{78}$.

Posteriormente, em Agosto de 1882, a revista semanal ilustrada Ciencia para todos publicava a seguinte notícia: «A cidade de Londres vai erigir uma estátua à memória do naturalista Darwin, glória da Inglaterra e um dos sábios mais distintos do nosso tempo. A estátua será de mármore e colocar-se-á na maior sala do museu britânico» ${ }^{79}$. No ano seguinte, lia-se na revista científica e literária $O$ Instituto: «Está já formada em Londres uma comissão para elevar uma estátua a Darwin e para criar um fundo destinado a promover o desenvolvimento das ciências biológicas. São membros desta comissão os arcebispos de Canterbury e de York, o bispo de Exeter, o deão de Westminster, de S. Paulo e de Christchurch, os duques de Argyll, Devonshire e Northumberland, o marquez de Salisburg, os condes de Derby, Ducis, Granville, Spencer, muitos pares de Inglaterra, muitos membros da Câmara dos Comuns, os chefes das universidades principais dos três reinos, e umas quarenta pessoas notáveis nas ciências físicas ou naturais. Os embaixadores de Alemanha, França e Itália, assim como os ministros da Suécia e América fazem parte desta comissão, o que dá à subscrição um carácter internacional» ${ }^{80}$.

$\mathrm{O}$ ano do quinquagésimo aniversário da publicação da obra darwiniana, Origem das espécies (1859-1909) coincidiu com o ano do centenário do nascimento de Darwin (1809-1909) e ainda do centenário da publicação da obra capital de Lamarck, a Filosofia zoológica (1809-1909). Esta tripla coincidência era uma excelente ocasião para se repensar a história do evolucionismo natural e o seu valor na cultura científica e humanística. Nas comemorações realizadas na Universidade de Cambridge em 22-23-24 de Junho, muitas Universidades e sociedades científicas de todo o mundo fizeram-se representar, desde a América ao Japão, da Índia à Austrália, passando pela Europa. Portugal teve como representantes, Egas F. Pinto Basto pela Universidade de Coimbra, em substituição de Júlio Augusto Henriques, delegado nomeado pela Universidade; Aarão Ferreira de Lacerda, pela Academia Politécnica do Porto e o médico Francisco Silva Teles pela Sociedade de Geografia de Lisboa e pelo Curso Superior de Letras ${ }^{81}$.

Francisco Silva Teles, o futuro defensor da racionalidade darwiniana na geografia ${ }^{82}$ resumiu a dupla celebração de Darwin em Cambridge, na sessão de 20 de Janeiro

\footnotetext{
77 Vide: Carlos França, «Le Professeur Barbosa du Bocage. 1823-1907. Éloge historique prononcé à la séance solennelle du 2 Mai 1908", Bulletin de la Société Portuguaise des Sciences Naturelles, Lisbonne, 2 (1-2) Nov. 1908, pp. 141-194.

78 Vide: Germano da Fonseca Sacarrão, «O darwinismo em Portugal», Prelo, Lisboa, (7), Abr.-Jun. 1985, pp. 13-15.

79 "À memoria de Darwin», Sciencia para Todos, Lisboa, 1 (30) 5 Ago. 1882, p. 238.

${ }^{80}$ A. de Candolle, «C. Darwin: Causas do successo de seus trabalhos e importancia d'elles», O Instituto, Coimbra, 30 (8) Fev. 1883, p. 360, nota C.

${ }^{81}$ Vide: Júlio Augusto Henriques, "Celebração do centenario do nascimento de Charles Darwin", Boletim da Sociedade Broteriana, Coimbra, 24, 1908-1909, pp. 245-246; Idem, "Carlos Darwin 1809-1909", Boletim da Sociedade Broteriana, Coimbra, 24, 1908-1909, pp. 5-6.

${ }^{82}$ Vide: Francisco Silva Teles, "O conceito scientifico da geografia», Revista da Universidade de Coimbra, Coimbra, 4, 1915, pp. 109-136.
} 
de 1910 da Sociedade portuguesa de ciências naturais ${ }^{83}$, constituída largamente por médicos ${ }^{84}$. Por seu turno, Aarão Ferreira de Lacerda, doutor pela Faculdade de Filosofia da Universidade e médico pela Escola Médico-Cirúrgica do Porto, relatou minuciosamente os eventos comemorativos realizados pela Universidade de Cambridge ${ }^{85}$, dando especial relevo aos discursos científicos e ao lançamento da publicação por Francis Darwin do esboço da doutrina darwiniana, escrito em $1842^{86}$. No breve historial da teoria da evolução que completa o seu artigo, Aarão Ferreira de Lacerda valorizou Lamarck enquanto precursor de Darwin e sublinhou que a inauguração do monumento a Lamarck no Museu de História Natural de Paris, em 13 de Junho de 1909, simbolizava a justa consagração da memória do naturalista francês. No entanto, defendeu que a mudança de paradigma da história natural foi operada pela Origem das espécies (1859) e não pela Filosofia zoológica (1809), de Lamarck.

Curiosamente, quem nesse ano memorável de 1909 trouxe a figura e a obra de Lamarck para primeiro plano na história do evolucionismo natural foi Raúl Proença, nas colunas do jornal $A$ Republica ${ }^{87}$. Neste sentido, após a exposição da filosofia lamarckiana da natureza, concluiu: «Foi só com Darwin que a teoria da evolução venceu o fixismo e se impôs a todo o mundo, mas o pai da doutrina, o génio formidável que a concebeu - foi o grande biologista francês»" 88 . O «insucesso" de Lamarck é justificado por três razôes fundamentais: o criacionismo dominante, sustentado pelos maiores naturalistas; a influência da grande autoridade de Cuvier, defensor do fixismo das espécies, e a insuficiente base de dados factuais e experimentais, disponíveis no princípio do século XIX. Cinquenta anos mais tarde, com Darwin, já não era possível impedir a falência do modelo criacionista na história natural.

No entanto, para Raúl Proença, o pioneiro genial fora Lamarck, razão pela qual não concorda que, com o triunfo de Darwin, o evolucionismo passasse a denominar-se "Darwinismo duma maneira tão injusta como falsa» ${ }^{89}$. E o combativo jornalista acrescentava: «Deram ao mundo novo descoberto por Lamarck o nome dum ousado explorador que não o descobriu. (...) É preciso colocar a obra de Lamarck no seu

${ }^{83}$ Vide: "Centenario de Darwin», Medicina Contemporanea, Lisboa, sér. II, 13(5) 30 Jan. 1910, p. 37.

${ }^{84}$ Vide: Joaquim da Silva Tavares, "A Sociedade Portugueza de Sciencias Naturais», Broteria, Lisboa, 6 - 3 a parte (sér., Vulgarização Scientifica), 1907, pp. 127-134.

85 Vide: Aarão Ferreira de Lacerda, "A commemoração darwineana celebrada pela Universidade de Cambridge», Annais Scientificos da Academia Polytechnica do Porto, Porto, 5 (3), 1910; P.L., "Literatura medica. Aarão de Lacerda, A commemoração darwineana celebrada pela Universidade de Cambridge (22-24 de Junho de 1909), Gazeta dos Hospitais do Porto, Porto, 4 (18) 15 Set. 1910, pp. 280-281.

${ }^{86}$ Vide: Charles Darwin, The foundations of the origin of species, a sketch written in 1842. ob. cit.. A Universidade de Cambridge publicou uma obra fundamental: A. C. Seward (ed.), Darwin and modern science. Essays in commemoration of the centenary of the birth of Charles Darwin and of the fiftieth anniversary of the publication of The origin of species. Edited, for the Cambridge Philosophical Society and the syndics of the University Press, by A. C. Seward. Cambridge, At The University Press, 1909.

${ }^{87}$ Raúl Proença, «Os grandes typos humanos. V-Lamarck», A Republica, Lisboa, 2 (353) 21 Mai. 1909, pp. 1-2; 2 (354) 22 Mai. 1909, pp. 1-2.

${ }^{88}$ Idem, ibidem, 2 (353) 21 Mai. 1909, p. 2.

${ }^{89}$ Idem, ibidem. Sublinhado do Autor. 
verdadeiro lugar» ${ }^{90}$. O contributo de Darwin para a teoria da evolução era situado, apenas, ao nível do factual, do empírico, e era válido porque demonstrava o mecanismo evolucionário lamarckiano. Na óptica de Raúl Proença, foi Lamarck quem construiu "toda a teoria da evolução: formação de caracteres novos pela influência do hábito, em relação íntima com o meio; transmissão desses caracteres adquiridos pelo mecanismo da hereditariedade: evolução individual, evolução das espécies»" ${ }^{11}$. Igualmente, "a teoria de que o homem descende do macaco, cuja prioridade se atribui a Darwin, pertence-lhe» ${ }^{92}$. Por fim, a teoria lamarckiana da evolução naturaliza o homem sem o desumanizar, pela fundamentação científica da «apologia mais fervorosa do esforço» ${ }^{93}$. Pelo contrário, na teoria de Darwin, o esforço, a vontade e o querer do homem pouco ou nada valem face à selecção natural, e esta não dá garantias de progresso ético e social. Assim, Darwin deve ser lido lamarckianamente, isto é, no quadro da ideia teleológica de evolução enquanto progresso ${ }^{94}$, a única que torna possível e previsível a realização da virtude, da justiça e da solidariedade social. Inteligentemente, Raúl Proença compreendeu que a teoria evolucionária de Darwin não podia caucionar a defesa do progresso em direcção aos valores socio-políticos referidos.

Por seu turno, também, Miguel Bombarda revelou-se crítico da substância essencial da teoria darwiniana, isto é, da selecção natural. Na sessão de 19 de Fevereiro de 1909, da Academia das Ciências de Lisboa ${ }^{95}$, valorizou a obra revolucionária de Darwin nas ciências naturais e humanas, mas fez notar que «a noção da transformação das espécies penetrou rapidamente todos os espíritos mercê de um erro - a selecção natural, que hoje se demonstrou não ser tanto quanto Darwin supunha a alavanca do transformismo»" ${ }^{96}$. A notícia desta intervenção de Miguel Bombarda foi publicada em A Medicina Contemporanea e aí reafirma-se que a teoria da evolução penetrou toda a cultura científica e humanística através de uma "alavanca falsa»: a selecção natural. O valor da revolução darwiniana era inquestionável, mas «as ideias lamarckianas dominam a ciência em toda a doutrina do transformismo» 97 . Na conferência que realizou na Academia de Estudos Livres, em Julho de 190998, Miguel Bombarda volta a sublinhar que a selecção natural não é a resposta científica ao problema do mecanismo

${ }^{90}$ Idem, ibidem

${ }^{91}$ Idem, ibidem. Sublinhado do Autor.

92 Idem, ibidem.

93 Idem, ibidem. Sublinhado do Autor.

${ }^{94}$ Vide: Raúl Proença, «Factos-A proposito do centenario de Darwin. O principio de Malthus-contradições d'um sabio do paiz da democracia real", A Republica, Lisboa, 2(362) 1 Jun. 1909, p. 1.

95 Miguel Bombarda, "[Intervenção na sessão de 19 de Fevereiro de 1909 da Academia das Sciencias de Lisboa a propósito do centenário de Darwin]", Actas das Sessóes da Primeira Classe. Academia das Sciencias de Lisboa, Lisboa, 2, 1905-1910, pp. 118-119.

96 Idem, ibidem, p. 118.

97 "Academia Real das Sciencias. Sessão de 19 de Fevereiro de 1909", A Medicina Contemporanea, Lisboa, sér. II, 12 (9) 28 de Fev. 1909, p. 71.

98 «Na Academia de Estudos Livres. Na próxima segunda-feira, pelas 9 horas da noite, realiza o sr. Dr. Miguel Bombarda uma conferencia comemorativa do centenário de Darwin», O Mundo, Lisboa, 9 (3111) 2 Jul. 1909, p. 2. 
evolucionário dos organismos vivos ${ }^{99}$. Por isso, persistiam divergências intra-científicas quanto ao modo como se processa a evolução orgânica, mas o fundamental é que elas não retiravam solidez à filosofia científica do universo: o monismo materialista-evolucionista, sistematizado pelo expoente do darwinismo alemão, Ernst Hæckel ${ }^{100}$. Inevitavelmente, dado o perfil psicológico e político de Miguel Bombarda, a sua homenagem ao sábio naturalista inglês converteu-se numa acção de combate anti-clerical e anti-teológico. O nome de Darwin seria também usado com idênticos objectivos político-culturais por livre pensadores operários, como o socialista Guedes Quinhones ${ }^{101}$.

Resumindo: em 1882, exceptuando o artigo de Júlio Augusto Henriques, todos os restantes, mesmo o de Arruda Furtado, acentuam a projecção de Darwin na cultura humanística, partindo da leitura biológica do ser histórico e social do homem feita pelo naturalista inglês. Em 1909, reflecte-se vivamente, entre nós, a competição entre a Inglaterra e a França pela paternidade da "revolução copernicana» nas ciências da vida e do homem.

Sem dúvida, Júlio Augusto Henriques formou sucessivas gerações que continuaram a defender o darwinismo na botânica, na zoologia e na antropologia. Não podia ser de outro modo, atendendo à própria história do paradigma darwinista (com ou sem Lamarck) na história natural desde 1859 até hoje.

Por outro lado, também em Portugal a teoria biológica da evolução foi invocada, usada e abusada enquanto arma científica na luta político-cultural, sobretudo desde os anos oitenta do século XIX até aos anos 20 do século XX, grosso modo. p. 3.

${ }^{99}$ Vide, também, "Conferencia do sr. dr. Miguel Bombarda», O Mundo, Lisboa, 9 (3115) 6 Jul. 1909,

100 Vide: «No centenario de Darwin. Brilhante conferencia do sr. Dr. Miguel Bombarda», A Vanguarda, Lisboa, 12 (19) 6 Jul. 1909, p. 1.

${ }^{101}$ Vide: "Conferencia», A Voz do Operario, Lisboa, 30 (1559) Set. 1909, p. 1; Guedes Quinhones, «Darwin», A Voz do Operario, Lisboa, 30 (1559) Set. 1909, p. 1. 
(Página deixada propositadamente em branco) 


\section{Calecçẫa \\ ป Ciências e Culturas Caimbra 2006}

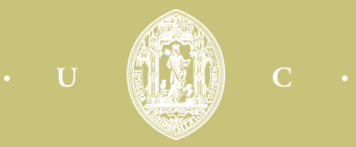

